\title{
Rapid production of hollow SS316 profiles by extrusion based additive manufacturing
}

Kedarnath Rane, Salvatore Cataldo, Paolo Parenti, Luca Sbaglia, Valerio Mussi, Massimiliano Annoni, Hermes Giberti, and Matteo Strano

Citation: AIP Conference Proceedings 1960, 140014 (2018); doi: 10.1063/1.5035006

View online: https://doi.org/10.1063/1.5035006

View Table of Contents: http://aip.scitation.org/toc/apc/1960/1

Published by the American Institute of Physics

\section{Articles you may be interested in}

Electron beam additive manufacturing with wire - Analysis of the process

AIP Conference Proceedings 1960, 140015 (2018); 10.1063/1.5035007

Investigation on bending failure to characterize crashworthiness of 6xxx-series aluminium sheet alloys with bending-tension test procedure

AIP Conference Proceedings 1960, 150004 (2018); 10.1063/1.5035011

Characterization of zinc alloy by sheet bulging test with analytical models and digital image correlation AIP Conference Proceedings 1960, 150015 (2018); 10.1063/1.5035022

Characterization of the austenitic stability of metastable austenitic stainless steel with regard to its formability AIP Conference Proceedings 1960, 150012 (2018); 10.1063/1.5035019

Mechanical properties of sheet metal components with local reinforcement produced by additive manufacturing AIP Conference Proceedings 1960, 160028 (2018); 10.1063/1.5035054

Ray tracing method for simulation of laser beam interaction with random packings of powders

AIP Conference Proceedings 1939, 020028 (2018); 10.1063/1.5027340 


\title{
Rapid Production of Hollow SS316 Profiles by Extrusion based Additive Manufacturing
}

\author{
Kedarnath Rane $^{1, \mathrm{a})}$, Salvatore Cataldo ${ }^{1, \mathrm{~b})}$, Paolo Parenti ${ }^{1, \mathrm{c})}$, Luca Sbaglia $^{1, \mathrm{~d})}$, \\ Valerio Mussi ${ }^{2, \mathrm{e})}$, Massimiliano Annoni ${ }^{1, \mathrm{f})}$, Hermes Giberti ${ }^{1, \mathrm{~g})}$, Matteo Strano ${ }^{1, \mathrm{~h})}$ \\ ${ }^{1}$ Dipartimento di Meccanica, Politecnico di Milano, Via La Masa 1, Milan, Italy \\ ${ }^{2}$ MUSP - Machine Tools and Production Systems, 29122 Piacenza, Italy \\ a) Corresponding author: kedarnath.rane@polimi.it, Tel: +39-0223998534, \\ ${ }^{b)}$ salv.cataldo@gmail.com, ${ }^{c)}$ paolo.parenti@polimi.it, ${ }^{d)}$ luca.sbaglia@gmail.com, evvalerio.mussi@musp.it, \\ f)massimiliano.annoni@polimi.it, ${ }^{g}{ }^{g}$ hermes.giberti@polimi.it, ${ }^{h}$ matteo.strano@polimi.it
}

\begin{abstract}
Complex shaped stainless steel tubes are often required for special purpose biomedical equipment. Nevertheless, traditional manufacturing technologies, such as extrusion, lack the ability to compete in a market of customized complex components because of associated expenses towards tooling and extrusion presses. To rapid manufacture few of such components with low cost and high precision, a new Extrusion based Additive Manufacturing (EAM) process, is proposed in this paper, and as an example, short stainless steel 316L complex shaped and sectioned tubes were prepared by EAM.

Several sample parts were produced using this process; the dimensional stability, surface roughness and chemical composition of sintered samples were investigated to prove process competence. The results indicate that feedstock with a 316L particle content of 92.5 wt. \% can be prepared with a sigma blade mixing, whose rheological behavior is fit for EAM. The green samples have sufficient strength to handle them for subsequent treatments. The sintered samples considerably shrunk to designed dimensions and have a homogeneous microstructure to impart mechanical strength. Whereas, maintaining comparable dimensional accuracy and chemical composition which are required for biomedical equipment still need iterations, a kinematic correction and modification in debinding cycle was proposed.
\end{abstract}

Keywords: Extrusion, Stainless steel 316L, tubes

\section{INTRODUCTION}

Several additive manufacturing techniques like Stereolithography (SLA) [1], Ink-jet Printing [2], Selective Laser Sintering (SLS) [3], and Laminated Object Manufacturing (LOM) [4] have been developed to fabricate three dimensional metallic components trough layer by layer addition of metallic materials. Extrusion-based methods for metal 3D printing are among the latest approaches for freeform fabrication of metallic components offer simplicity, low cost fabrication system, high density of fabricated parts, low material wastage and capability of producing parts with multiple materials. The conventional extrusion forming requires high pressure and high temperatures for complex shapes [5]. Energy inefficiency, associated high thermal stresses in the tools and wear problems demand alterative manufacturing solutions when low batch production is required.

Most important extrusion-based additive processes include Fused Deposition of Metals/Ceramics (FDM/C) Extrusion Freeform Fabrication (EFF), Robocasting (RC), and Freeze-form Extrusion Fabrication (FEF). FDM/C developed by Danforth [6] uses a commercial Fused Deposition Modeling (FDM) system from Stratasys Inc. to extrude metal/ceramic powder-loaded thermoplastic filaments. The filament was melted, extruded, and re-solidified to retain its shape. EFF [7] technique utilizes extrusion of slurries to produce three-dimensional components. Slurries are freeform deposited onto a heated platen to develop their shape. RC [8] is another freeform extrusion fabrication process, advantageous over EFF and FDC with respect to the lower $(<10 \mathrm{wt} \%)$ amount of binder in the 
feedstock which facilitates pre-processing and post-processing. An aqueous suspension from powdered materials is prepared and extruded on to a hot plate to dry and maintain its shape. In the FEF process [9], a high ( $>50$ vol\%) solids loading aqueous paste containing 1-4 vol\% organic additives is extruded in a freezing environment to solidify the paste after its deposition. For FDM/C, the feedstock preparation is a multistep process. The filament must also maintain a very high dimensional tolerance to ensure consistent flowrates [10]. The non-uniform drying in RC causes warpage and cracks in the parts. In FEF process, ice crystal formation during the freezing process and weak layer-to-layer bonding reduce the relative density and mechanical properties of sintered 3D printed parts. Nozzle clogging is another difficulty in this process, due to powder agglomerates and binder segregations in the feedstock.

In this paper, as an attempt to overcome the above limitations, a new process (which combines fused deposition modelling and metal injection moulding) is proposed. The feedstock is prepared in a similar fashion as in metal injection moulding. The processing route for the fabrication of complex geometries was illustrated by producing several parts. Moreover, the proposed method needs few modifications during deposition and binder removal step.

\section{PROCESS OVERVIEW AND CAPABILITIES}

The feedstock extrusion process described in this paper has several steps. Dry powders are mixed together to customise the chemical composition of metal (if pre alloyed powders/ composite mixtures are not available). The mixture of metal particles and organic binder is prepared at melting temperatures of binder constituents. This mixture is processed through extruder for homogenization and then palletised for ease of handling. The specially designed and developed extrusion based additive manufacturing machine allow distinct control over extrusion system and parallel kinematic table for customised printing $[11,12]$. The prepared feedstock (pelletised mixture) is extruded at controlled flowrates through a nozzle for deposition. Plunger based extrusion system is attached to a PLC controller to regulate the flow of molten feedstock through nozzle. Kinematic table is attached to PLC motion system which regulates $\mathrm{X}, \mathrm{Y}$ and $\mathrm{Z}$ directions movement through $\mathrm{G} \& \mathrm{M}$ code commands provided by tool-path planning software. The extrudate is deposited on a heated platter for building the 3D object. A schematic of the process is shown in Fig. 1. Once the 3D deposition is completed, the fabricated part is debinded in agitated water to remove sacrificial binder and in oven to remove backbone binder. Sintering is the final and most important postprocessing phase, during which part is heated at elevated temperatures in a controlled atmosphere to densify and stabilise the shape.

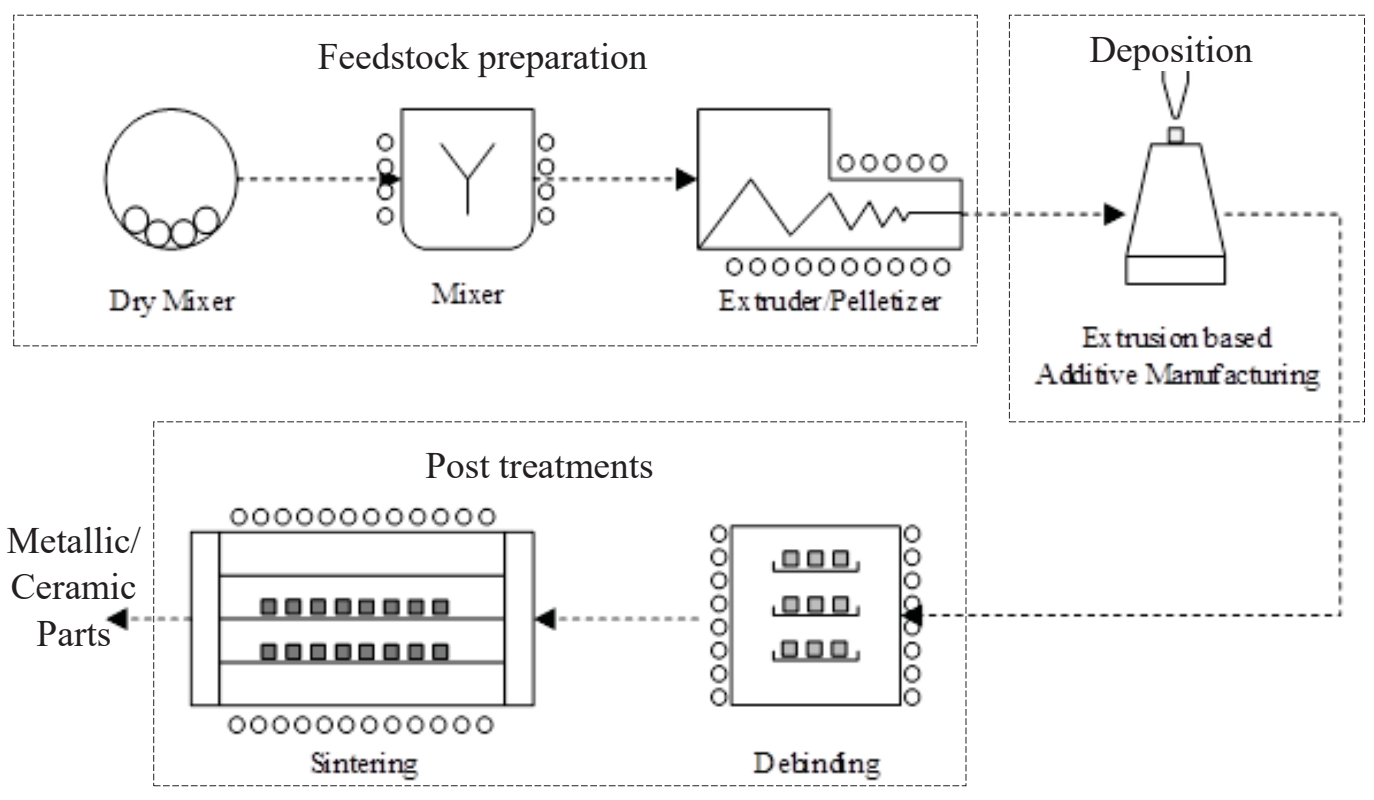

FIGURE 1: Process overview of Extrusion based additive manufacturing of metal and ceramic objects 


\section{MATERIALS AND METHODS}

\section{Feedstock Preparation}

A $92.5 \mathrm{wt} \%$ (62 vol\%) solids loading in stainless steel feedstock was prepared by adopting a commercially available 316L stainless steel powder, $\mathrm{D}_{50} 8.8 \mu \mathrm{m}$ (Sandvik Osprey, UK) used for metal injection molding. Other constituent of feedstock is Embemould K83, a binder mixture which was procured from eMBe. Batch wise feedstock mixing was carried out using a twin screw compounder (by Brabender). In each batch, $250 \mathrm{~g}$ of feedstock was prepared. Calculated amount of powder and binder were churned at $140^{\circ} \mathrm{C}$ for 30 minutes to mix the feedstock homogeneously without introducing air bubbles. Finally, feedstock was processed through extruder and palletised in $2.5 \mathrm{~mm}$ sized granules.

\section{Extrusion based 3D deposition}

The CAD model of part in STL file format was proceed in the Slic3r program to obtain a G-code. Printing settings like layer thickness, raster spacing, extrusion speed, table speed were incorporated during generation of $G$ code for tool path of a part. Extrusion based additive manufacturing system as shown in Fig. 2 (a) was used for preparing 3D objects of SS316L feedstock. This G code is read by MT Developer 2 motion program which controls the flow of feedstock through nozzle and kinematic table. Feedstock granules were supplied to loader. The material is heated in loader and in molten form it moved to the extrusion chamber. Motion program simultaneously controls extrusion and kinematic sub systems to obtain the 3D object of a given shape. Various sample shapes were produced with SS316L feedstock at an extrusion temperature of $120^{\circ} \mathrm{C}$ with extrusion and table speed of $10 \mathrm{~mm} / \mathrm{s}$.

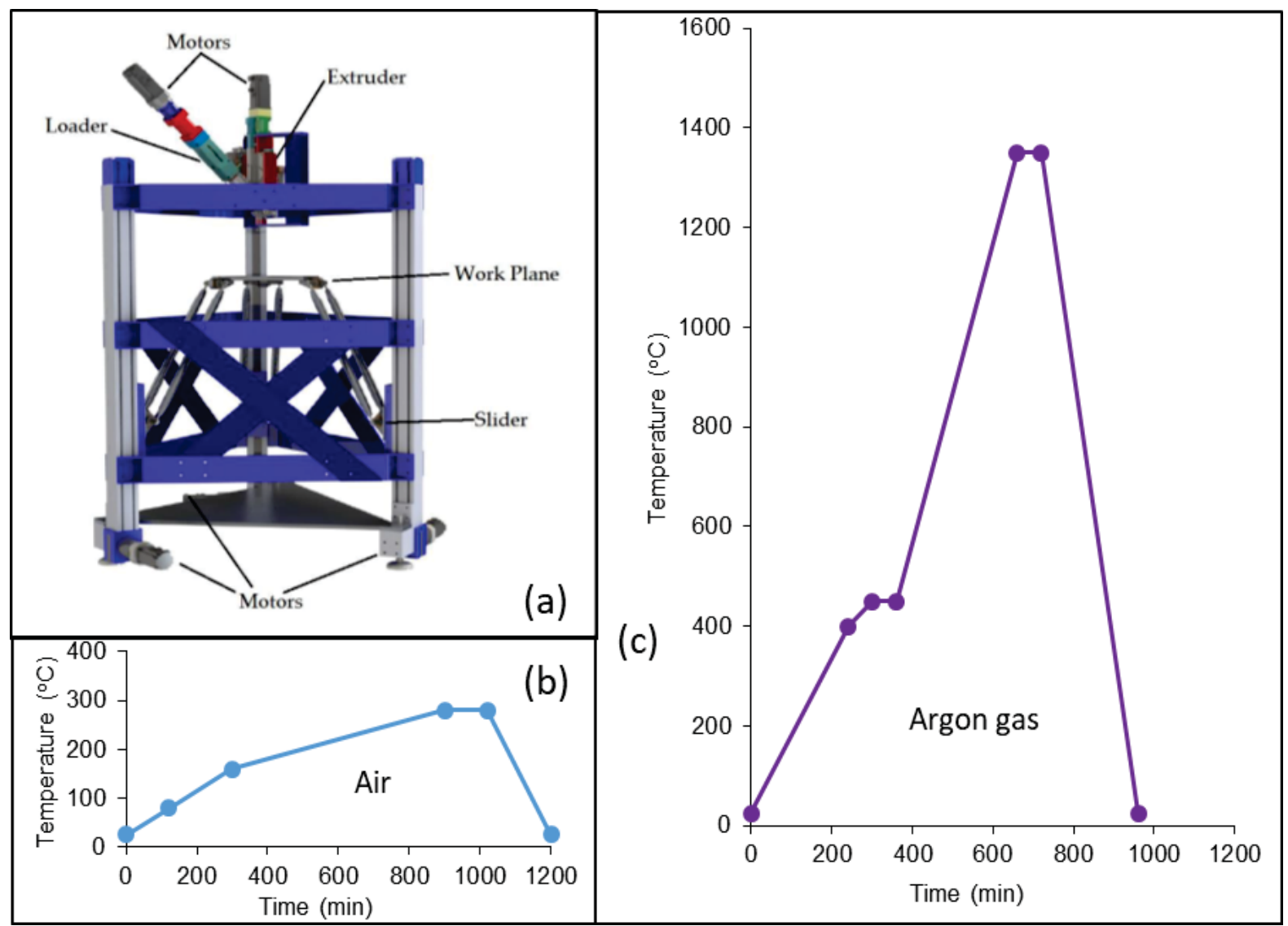

FIGURE 2: (a) Extrusion based additive manufacturing machine, heating and cooling cycle used for postprocessing of $3 D$ printed SS316L parts (b) Thermal debinding and (c) sintering 


\section{Debinding and Sintering}

Two stage debinding method was used to eliminate the binder constituents from printed part. In the first step, the parts were placed for about 10 hours in agitated water at $40^{\circ} \mathrm{C}$. After the first stage of debinding, parts were dried. Then in oven, these parts were thermal debinded in air at $280^{\circ} \mathrm{C}$ (heating and cooling cycle used for thermal debinding is shown in Fig. 2 (b)). During thermal debinding, heating rate of $1^{\circ} \mathrm{C} / \mathrm{min}$ was chosen for the backbone binder burnout to avoid high weight reduction rates. The samples were then sintered in argon gas purge with a heating rate of $5{ }^{\circ} \mathrm{C} / \mathrm{min}$ in an electric furnace). They were sintered at the same temperatures $\left(1350^{\circ} \mathrm{C}\right)$ for an hour. As received powder, feedstock and sintered samples are analyzed for microstructure and chemical composition using Zeiss Evo 50 SEM microscope.

\section{RESULTS AND DISCUSSION}

\section{Parts Printed}

To examine the performance of extrusion based AM process in manufacturing of complex shaped tubes, numerous parts were printed. Fig. 3 (a) shows an examples of these parts, which are square, pentagon and hexagon sections of tubes in the green state. As could be seen from the picture, few of the visible printing flaw are observed in the green parts. These flaws are resulted due to difficulties in kinematic control.

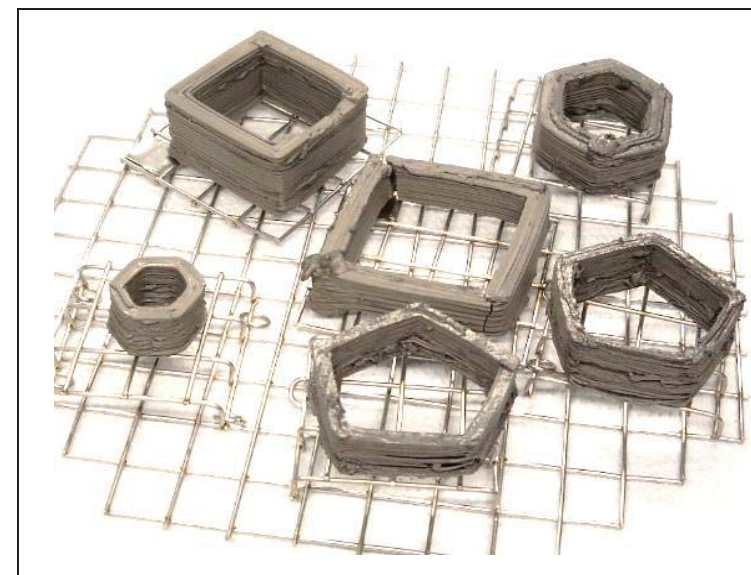

(a)

(b)

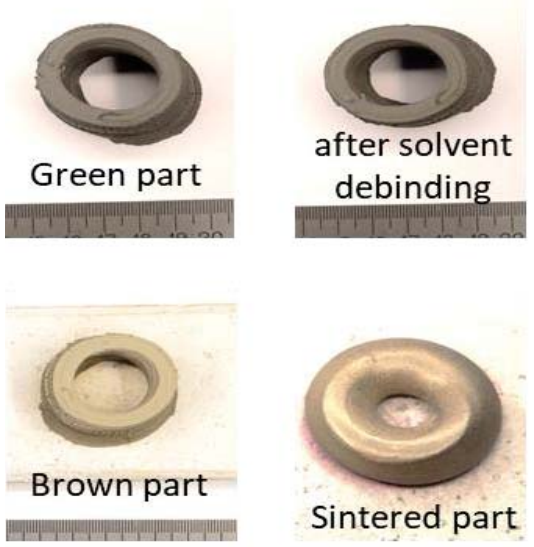

FIGURE 3: (a) variety of shapes printed using extrusion based AM machine (b) evolution of part during postprocessing

\section{Part characteristics during post-processing}

The density of the sintered parts were measured using Archimedes' technique. When using the sintering schedule as shown in Fig. 3 (b), the density of sintered samples are considerably lower (about 87 to $90 \%$ ) than the wrought density of SS316L material. This is partly due to voids caused during sintering of samples. The cumulative average weight loss of green parts during post processing suggests that, after solvent debinding: about $2.35 \%$ wt. loss (expected 4 to 5\%), after thermal debinding: approximate 6.60\% wt. loss (expected 8 to $9 \%$ ) and after sintering: total wt. loss $9.40 \%$, i.e. unexpected $3 \%$ wt. loss during sintering and still $0.6 \%$ binder residues in sintered part. This may be another cause for lower sintered density than expected 95-98\%. Few of the parts shows shape distortion which may be due to unexpected plastic deformation during sintering. The decomposition/ auto-catalytic exothermal reaction of backbone binder of $\mathrm{K} 83$ starts at $160^{\circ} \mathrm{C}$ and continues till $450^{\circ} \mathrm{C}$.

\section{Metallographic Analysis}

To analyse the causes of lower sintered density, metallurgical evaluation was carried out using SEMEDAX. Powder morphology (Fig. 4 (a)) shows that most of the particles are spherical with average particle size of about $8.5 \mu \mathrm{m}$. Homogeneous coating of binder is conformed after analysing fractured surface of feedstock (Fig. 4 (b)). 

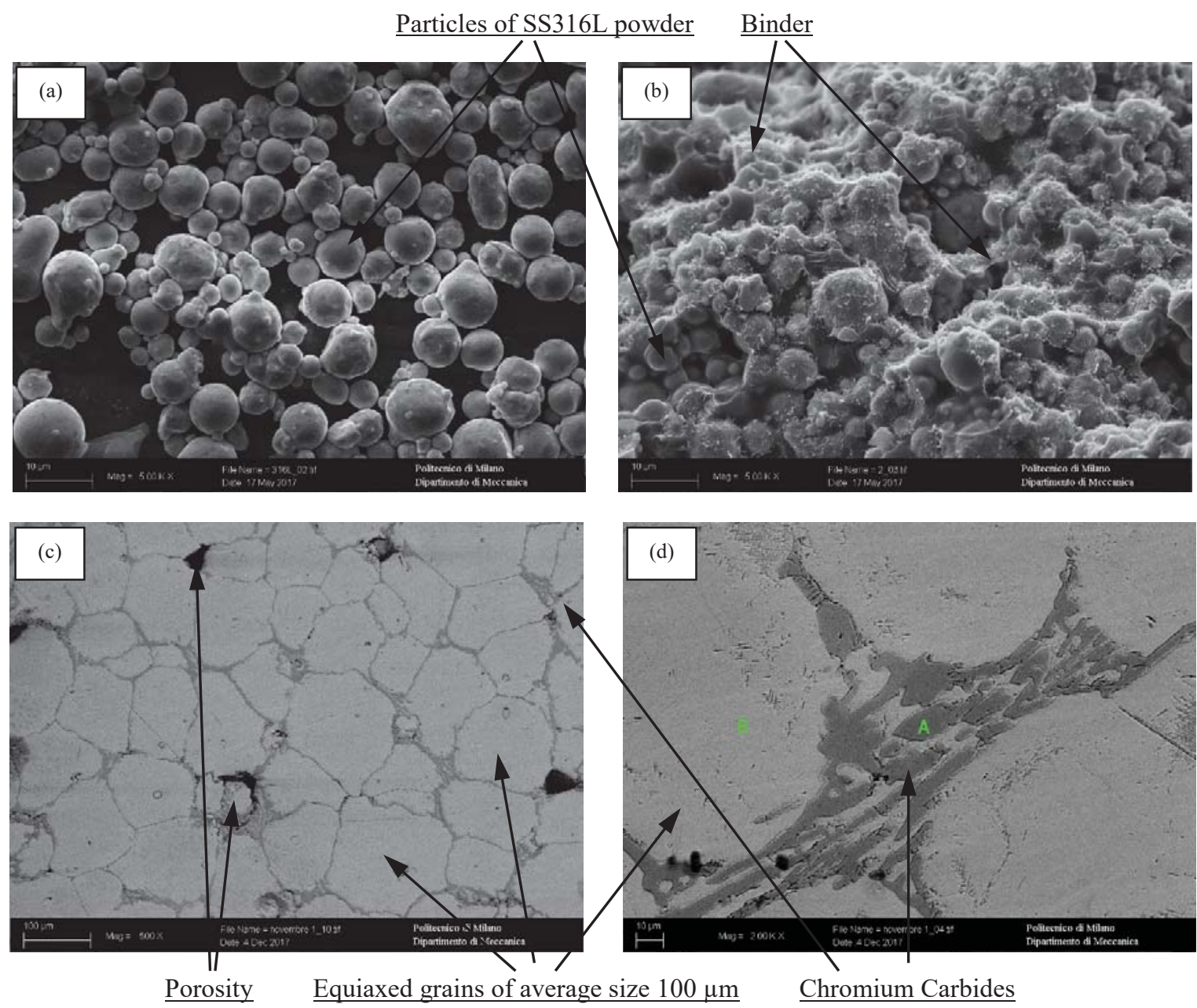

FIGURE 4: SEM micrographs of (a) SS316L powder, (b) SS316L feedstock having 92.5 wt.\% solid loading,

(c) sintered section of part and (d) chromium carbide reach grain boundaries in sintered microstructure

Section of sintered sample as shown in Fig. 3 (b) was analysed microstructure and chemical composition. Fig. 4 (c) shows the microstructure of a sintered sample (thermal debinding at $280^{\circ} \mathrm{C}$ and sintered at $1350^{\circ} \mathrm{C}$ ). $\mathrm{No}$ printing flaws are observed in these pictures. The grains are equiaxed and larger $(>85 \mu \mathrm{m})$, with the starting powder size of SS316L is about $8.5 \mu \mathrm{m}$. Grain growth is a result of higher sintering temperature, sintering time and diffusion of carbon during sintering. Levenfeld et. al discussed the formation of carbides during the cooling process, and it is the main cause the brittleness of the sintered sample. Chromium has low diffusivity in austenite, the precipitation induces a decrease in the amount of chromium in solid solution in austenite in the vicinity of the grain boundary [13]. Raza et. al suggested that the solid loadings below the critical loading (i.e., 65 vol.\%) and a rapid post-sintering cooling rate, i.e., $10^{\circ} \mathrm{C} / \mathrm{min}$ during vacuum sintering at $1325^{\circ} \mathrm{C}$ resulted in improved mechanical properties and no carbide formation across grain boundaries [14].

TABLE 1: Chemical composition (by wt.\%) of powder used in the present study

\begin{tabular}{cccccccc}
\hline Element & $\mathrm{Cr}$ & $\mathrm{Ni}$ & $\mathrm{Mo}$ & $\mathrm{Mn}$ & $\mathrm{Si}$ & $\mathrm{C}$ & $\mathrm{Fe}$ \\
\hline Powder & 17.90 & 11.70 & 2.30 & 1.41 & 0.72 & 00.02 & 65.92 \\
\hline $\mathrm{A}$ & 59.01 & 00.00 & 4.96 & 1.19 & 0.00 & 15.36 & 19.48 \\
\hline $\mathrm{B}$ & 15.55 & 11.70 & 1.66 & 1.27 & 0.70 & 05.81 & 63.80 \\
\hline
\end{tabular}


In the present case, residual carbon from debinding may be reacted with the Fe and Cr from SS316L and formed carbides across the grain boundaries as shown in in Fig. 4 (d). The elemental chromium and carbon at measuring location A as given in Table 1 conform formation of chromium carbides at grain boundaries. Stainless steel $316 \mathrm{~L}$ is susceptible to sensitization (the process by which chromium combines with carbon to form chromium carbides). The chromium is removed from areas close to the grain boundaries and leaves these areas depleted of chromium. The cooling rate during sintering is generally slow which increases the likelihood of chromium carbide formation. The higher level of carbon due to insufficient debinding can also increase the chance of sensitization. The higher level of carbon in solid solution of stainless steel and consequently improving the kinetics of grain growth. The powders with lower particle size were coated using the same load in deposition chamber that correspond to a significant decrease of coating thickness. Thus, an improvement of specific surface area corresponds to a significant loss of inhibition effect of grain growth. The low particle size is desired in extrusion based 3D printing to reduce the viscosity of feedstock and the solid volume content but it results in increase of surface are which also increases the grain size of sintered parts.

\section{CONCLUSIONS}

An extrusion based freeform fabrication process for producing thick walled SS316 parts was introduced in this paper. To examine the capabilities of the process, several parts for various shapes were built and their sintered characteristics were studied. This process has been shown to be able to produce complex shaped parts with near theoretical density $\sim 90 \%$ ) and a uniform microstructure. Effect of incomplete debinding stage was reflected on sintered density and chemical composition. The control over residual carbon in sintered part via prolonged debinding may reduce formation of chromium carbides and prevent undesirable grain growth.

\section{REFERENCES}

1. M. L. Griffith, J. W. Halloran (1996), Freeform fabrication of ceramics via stereolithography, J. Am. Ceram. Soc. 79, 2601-2608.

2. R. Noguera, M. Lejeune, T. Chartier (2005), 3D fine scale ceramic components formed by ink-jet prototyping process, J. Eur. Ceram. Soc. 25, 2055-2059.

3. E.A. Griffin, S. McMillin (1995), Selective laser sintering and fused deposition modeling processes for functional ceramic parts, in: Solid Free. Fabr. Symp., Austin, TX, USA, 25-30.

4. C. Griffin, J. Daufenbach, S. McMillin (1994), Desktop manufacturing: LOM vs pressing, Am. Ceram. Soc. Bull. 73, 109-113.

5. Hansson, S. (2010). Modeling of the stainless steel tube extrusion process (Doctoral dissertation, Luleå tekniska universitet).

6. S.C. Danforth (1995), Fused deposition of ceramics: a new technique for the rapid fabrication of ceramic components, Mater. Technol. 10, 144-146.

7. K. Stuffle, A. Mulligan, P. Calvert, J. Lombardi (1993), Solid freebody forming of ceramics from polymerizable slurry, in: Solid Free. Fabr. Symp., Austin, TX, USA, 60-63.

8. J. Cesarano III, R. Segalmen, P. Calvert (1998), Robocasting provides moldless fabrication from slurry deposition, Ceram. Ind. 148, 94-102.

9. T. Huang, M.S. Mason, G.E. Hilmas, M.C. Leu (2005), Freeze-form extrusion fabrication of ceramics, in: Solid Free. Fabr. Symp., Austin, TX, USA, 73-85.

10. S. Iyer, J. McIntosh, A. Bandyopadhyay, N. Langrana, A. Safari, S. C. Danforth, R. B. Clancy, C. Gasdaska, P. J. Whalen (2008), Microstructural characterization and mechanical properties of Si3N4 formed by fused deposition of ceramics, Int. J. Appl. Ceram. Technol. 5, 127-137.

11. Annoni, M., Giberti, H., \& Strano, M. (2016), Feasibility Study of an Extrusion-based Direct Metal Additive Manufacturing Technique. Procedia Manufacturing, 5, 916-927.

12. Giberti, H., Strano, M., \& Annoni, M. (2016), An innovative machine for Fused Deposition Modeling of metals and advanced ceramics. In MATEC Web of Conferences (Vol. 43). EDP Sciences.

13. Levenfeld, B., Varez, A. \& Torralba, J.M. (2002), Effect of residual carbon on the sintering process of M2 high speed steel parts obtained by a modified metal injection molding process. Metallurgical and Materials Transactions A 33, 1843-1851.

14. Raza, M. R., Ahmad, F., Muhamad, N., Sulong, A. B., Omar, M. A., Akhtar, M. N., \& Aslam, M. (2016), Effects of solid loading and cooling rate on the mechanical properties and corrosion behavior of powder injection molded 316 L stainless steel. Powder Technology, 289, 135-142. 